\title{
Big Five Content Representation of the Japanese Version of the Ten-Item Personality Inventory*
}

\author{
Atsushi Oshio $^{\text {1\# }}$, Shingo $\mathrm{Abe}^{2}$, Pino Cutrone ${ }^{3}$, Samuel D. Gosling ${ }^{4}$ \\ ${ }^{1}$ Faculty of Letters, Arts and Sciences, Waseda University, Tokyo, Japan \\ ${ }^{2}$ Baika Women's University, Osaka, Japan \\ ${ }^{3}$ Nagasaki University, Nagasaki, Japan \\ ${ }^{4}$ Department of Psychology, University of Texas, Austin, USA \\ Email: "oshio.at@waseda.jp
}

Received September $7^{\text {th }}, 2013$; revised October $13^{\text {th }}, 2013$; accepted November $12^{\text {th }}, 2013$

\begin{abstract}
Copyright (C) 2013 Atsushi Oshio et al. This is an open access article distributed under the Creative Commons Attribution License, which permits unrestricted use, distribution, and reproduction in any medium, provided the original work is properly cited. In accordance of the Creative Commons Attribution License all Copyrights (C) 2013 are reserved for SCIRP and the owner of the intellectual property Atsushi Oshio et al. All Copyright (C) 2013 are guarded by law and by SCIRP as a guardian.
\end{abstract}

\begin{abstract}
The Ten-Item Personality Inventory (TIPI) is a widely used, very brief measure of the Big Five personality dimensions (Gosling, Rentfrow, \& Swann, 2003). Recently, Oshio, Abe and Cutrone (2012) developed and validated a Japanese version of the TIPI. The present study focuses on evaluating the content validity of the TIPI-J with respect to the thirty facets of the Japanese version of the Revised NEO Personality Inventory (NEO-PI-R-J). 163 Japanese undergraduates (67 males and 96 females) completed the TIPI-J and the NEO-PI-R-J. The convergent correlations between the TIPI-J and the Big Five dimensions of the NEO-PI-R-J were as follows: $r=0.65$ (Extraversion), $r=0.49$ (Agreeableness), $r=0.63$ (Conscientiousness), $r=0.70$ (Neuroticism), and $r=0.46$ (Openness). Twenty-eight of thirty facets of the NEO-PI-R-J correlated positively with equivalent scales of the TIPI-J. A joint factor analysis of the five scales of the TIPI-J with the thirty facets of the NEO-PI-R-J showed clear indicators for the five known superordinate dimensions of personality in both scales. Results indicated that the TIPI-J provides an adequate representation of the Big Five dimensions of personality and correlates sufficiently well with the larger scale NEO-PI-R-J.
\end{abstract}

Keywords: Big Five Personality; Validity; NEO-PI-R; TIPI-J

\section{Introduction}

Prompted by the growth of Internet surveys, epidemiological studies, and repetitive investigations in daily settings, a number of very brief measurement scales have been recently developed and validated for various complex psychological constructs, such as those assessed by the Big Five personality scale. These very brief scales typically measure constructs using 1 - 4 items per construct as opposed to the traditional scales, which typically use a larger number of items. For example, while the traditional measures of the Big Five personality dimensions, such as the Revised NEO Personality Inventory (NEO-PI-R; Costa \& McCrae, 1992) and the NEO Five-Factor Inventory (NEO-FFI; Costa \& McCrae, 1992) use 60 and 10 items per scale, respectively, the very brief measures, such as the Ten-Item Personality Inventory (TIPI; Gosling, Rentfrow, \& Swann, 2003) include only two.

The main motivations driving the development of these

${ }^{*}$ This research contains reanalyzed data originally presented by the authors in a poster session entitled "Coverage area of OCEAN personality dimensions: Does the Ten Item Personality Inventory (TIPI-J) adequately represent the Big-Five dimensions of personality?" at the 3rd Biennial Conference of the Association for Research in Personality, Charlotte, North Carolina, USA, in 2013.

${ }^{\#}$ Corresponding author. very brief measures of personality are both practical and psychometric (Credé, Harms, Niehorster, \& Gaye-Valentine, 2012). Very brief scales are practical because participants require less time to complete them, and they are less likely to cause boredom and fatigue. Moreover, considerable evidence has accumulated regarding the psychometric reliability and validity of these very brief measures (e.g., Gosling et al., 2003; Jonason \& Webster, 2010; Robins, Hendin, \& Trzesniewski, 2001; Thalmeyer, Saucier, \& Eigenhuis, 2011).

Aoki (1971) conducted a psycho-lexical study in Japan by compiling a list of approximately 6000 Japanese words that reflect personality traits and selected 455 of them using the same procedures as Allport and Odbert (1936). Subsequently, Aoki (1976) selected 98 Japanese personality words again and obtained seven factors from them. After that, various studies have identified the Big Five personality structures in Japan (Kashiwagi, Wada, \& Aoki, 1993; Kashiwagi, Tsuji, Fujishima, \& Yamada, 2005; Murakami, 2003; Wada, 1996). A cross-national twin study (Yamagata et al., 2006) also revealed five factors of the NEO-PI-R that were highly congruent across samples from three countries: Canada, Germany, and Japan. These studies indicate that the five-factor structure of personality is common also in Japan.

Several very brief measures have been developed to assess 
the Big Five personality dimensions (Aronson, Reilly, \& Lynn, 2006; Bernard, Walsh, \& Mills, 2005; Gosling et al., 2003; Rammstedt \& John, 2007; Woods \& Hampson, 2005). In Japan, Namikawa et al. (2012) tried to reduce the number of items of the Big Five scale, which consists of adjectives, based on the earlier work of Wada (1996). They selected 29 items by using an item response theory (IRT) model and explored the relations between the item-reduced version of the Big Five Scale and the Japanese version of the NEO-FFI (Shimonaka, Nakazato, Gondo, \& Takayama, 1999). However, with 29 items, this item-reduced version is still considerably longer than the typical length of the very brief instruments.

Oshio, Abe, and Cutrone (2012) used a multi-step procedure to develop a very brief Japanese measure of the Big Five personality dimensions, called the Japanese version of the Ten-Item Personality Inventory (TIPI-J). First, they translated all ten items of the original TIPI (Gosling et al., 2003) into Japanese. Five preliminary studies were conducted, and the mode of expression of each item was further refined in order to avoid deviations from a normal distribution and to ensure appropriate correlations between corresponding items. Second, the revised items of the TIPI-J were translated back into English and the final version was checked and, subsequently, deemed sufficient by the TIPI's original creator. Third, two types of reliability measures of the TIPI-J were examined: internal consistency and test-retest reliability. Correlation coefficients between within-scale (oppositely keyed) items ranged from -0.28 (neuroticism) to -0.59 (extraversion), and the test-retest reliability for 2-week intervals ranged from 0.62 (openness) to 0.77 (extraversion). Overall, the reliability of the TIPI-J almost equaled that of the original English language version (Gosling et al., 2003). Fourth, convergent and discriminant validities of the TIPI-J were explored by examining the correlations between the TIPI-J and five other Big Five scales in Japan, namely the FFPQ-50 (Fujishima, Yamada, \& Tsuji, 2005), Big Five (Murakami \& Murakami, 1999), NEO-FFI (Shimonaka et al., 1999), BFS short version (Uchida, 2002), and BFS (Wada, 1996). Fifth, correlation analyses between self-rated and friend-rated TIPI-J scores for extraversion, conscientiousness, and openness showed significant positive correlations between the two ratings.

The present study further explores the validity of the TIPI-J. The TIPI-J has only ten items; therefore, there is a risk that it could assess only a tiny fraction of the broad content of the Big Five personality domains. Here, this study focuses on content validity, which is the degree to which elements of an assessment instrument are relevant to and representative of the targeted construct for a particular assessment purpose (Haynes, Richard, \& Kubany, 1995). In the present study, the content validity of the Big Five personality dimensions assessed by the TIPI-J is evaluated through the content coverage of the TIPI-J with respect to the 30 facets of the Japanese version of the NEO-PI-R.

\section{Method}

\section{Participants}

A total of 163 Japanese undergraduates (67 males and 96 females) participated in this study. Their average age was 19.0 years $(\mathrm{SD}=1.2)$. All participants were recruited via psychology lectures at three universities that are located in Tokyo, Aichi, and Osaka prefecture.

\section{Materials}

TIPI-J. The TIPI-J developed by Oshio et al. (2012) was used. The TIPI-J consists of 10 items, with two items assessing each dimension. For each dimension, one item is positively keyed and the other is negatively keyed. Items are rated on a 7-point scale ranging from 1 (disagree strongly) to 7 (agree strongly). Within-scale correlations between the positively and negatively keyed items on each scale were $-0.27,-0.53,-0.35,-0.21$, and -0.45 for neuroticism, extraversion, openness, agreeableness, and conscientiousness, respectively.

Japanese version of the NEO-PI-R (NEO-PI-R-J). The Japanese translated version of the Revised NEO Personality Inventory (Costa \& McCrae, 1992) developed by Shimonaka et al. (1999) was used. Each of the items was rated on a 5-point scale ranging from 0 (disagree strongly) to 4 (agree strongly). In the sample of this study, Cronbach's alpha coefficients were $0.87,0.91,0.79$, 0.86 , and 0.90 for neuroticism, extraversion, openness, agreeableness, and conscientiousness, respectively. The coefficient alpha values for the facet scales of the Japanese version of NEOPI-R ranged from 0.62 to 0.81 for neuroticism, from 0.48 to 0.78 for extraversion, from 0.14 to 0.76 for openness, from 0.48 to 0.78 for agreeableness, and from 0.55 to 0.77 for conscientiousness. The coefficient alphas of some of the facets ("Excitementseeking", "Actions", and "Modesty") were low (0.48, 0.42, and 0.48 , respectively), and the coefficient alpha of the Values facet of openness was even lower (0.14), as were some other coefficients. Nevertheless, since the meaning and content of each facet factor were thought to be important, we followed Shimonaka et al. (1999) in using all scores.

\section{Statistical Analyses}

We used IBM SPSS 20.0 to compute Pearson product-moment correlation coefficients and conduct factor analyses. In the joint factor analysis, the five subscales of the TIPI-J were factored jointly with the 30 facet factors of the NEO-PI-R in order to explore whether the structure of the TIPI-J corresponds to the Big Five components.

\section{Results}

\section{Correlation between TIPI-J and the Five Factors of the NEO-PI-R-J}

To explore the convergent and discriminant validity of the TIPI-J with respect to the Big Five personality components, correlation analysis between the five subscales of the TIPI-J and the NEO-PI-R-J was performed (Table 1). Correlation coefficients between corresponding scales of the two instruments were significantly positive, ranging from 0.46 to 0.70 , with a mean of 0.59 . The Openness dimension of the TIPI-J had a moderately significant positive correlation with extraversion of the NEO-PI-R-J $(r=0.40, p<0.001)$, but the five correlation coefficients of the corresponding scales (on the diagonal in Table 1) were all higher than any of the off-diagonal coefficients.

\section{Correlation between TIPI-J and Facet Scales of the NEO-PI-R-J}

To examine the content coverage of the Big Five personality 


\section{A. OSHIO ET AL.}

dimensions assessed by the TIPI-J, correlation analysis between the TIPI-J scale scores and the scores of the facet scales of the NEO-PI-R-J was performed (Table 2). The mean correlation between the corresponding five TIPI-J scales and the 30 facets of the NEO-PI-R-J was 0.41 . The Neuroticism dimension of the
TIPI-J showed significant positive correlations with the six neuroticism facets of the NEO-PI-R-J, with a mean of 0.52 . The Extraversion dimension of the TIPI-J showed significant positive correlations with the six extraversion facets of the NEOPI-R-J, ranging from 0.37 to 0.59 , with a mean of 0.46 . Five

Table 1.

Correlations between the five factors of the TIPI-J and the Japanese version of the NEO-PI-R-J.

\begin{tabular}{|c|c|c|c|c|c|c|c|c|c|c|}
\hline & \multicolumn{10}{|c|}{ TIPI-J } \\
\hline & \multicolumn{2}{|c|}{ Neuroticism } & \multicolumn{2}{|c|}{ Extraversion } & \multicolumn{2}{|c|}{ Openness } & \multicolumn{2}{|c|}{ Agreeableness } & \multicolumn{2}{|c|}{ Conscientiousness } \\
\hline \multicolumn{11}{|l|}{ NEO-PI-R-J } \\
\hline Neuroticism & 0.70 & $* * *$ & -0.27 & ${ }^{* * *}$ & -0.17 & * & -0.34 & ${ }^{* * *}$ & -0.17 & $*$ \\
\hline Extraversion & -0.19 & $*$ & 0.65 & $* * *$ & 0.40 & $* * *$ & 0.21 & $* *$ & 0.18 & * \\
\hline Openness & -0.08 & & 0.17 & $*$ & 0.46 & $* * *$ & -0.02 & & 0.13 & \\
\hline Agreeableness & -0.14 & & 0.06 & & -0.04 & & 0.49 & ${ }^{* * *}$ & 0.11 & \\
\hline
\end{tabular}

Note: ${ }^{*} p<0.05,{ }^{* *} p<0.01,{ }^{* * *} p<0.001$.

Table 2.

Correlations between the TIPI-J and facet scores of the Japanese version of the NEO-PI-R-J.

\begin{tabular}{|c|c|c|c|c|c|c|c|c|c|c|c|}
\hline & \multicolumn{10}{|c|}{ TIPI-J } & \multirow{2}{*}{$\begin{array}{c}\text { Coefficient } \\
\text { alpha }\end{array}$} \\
\hline & \multicolumn{2}{|c|}{ Neuroticism } & \multicolumn{2}{|c|}{ Extraversion } & \multicolumn{2}{|c|}{ Openness } & \multicolumn{2}{|c|}{ Agreeableness } & \multicolumn{2}{|c|}{ Conscientiousness } & \\
\hline N1: Anxiety & 0.63 & *** & -0.30 & ${ }^{* * *}$ & -0.15 & & -0.08 & & -0.04 & & 0.79 \\
\hline N2: Angry Hostility & 0.45 & ${ }^{* * *}$ & -0.13 & & -0.08 & & -0.55 & $* * *$ & -0.08 & & 0.81 \\
\hline N3: Depression & 0.58 & ${ }^{* * *}$ & -0.20 & ** & -0.25 & ${ }^{* *}$ & -0.24 & ${ }^{* *}$ & -0.14 & & 0.79 \\
\hline N4: Self-Consciousness & 0.52 & ${ }^{* * *}$ & -0.41 & ${ }^{* * *}$ & -0.27 & $* * *$ & -0.13 & & -0.09 & & 0.62 \\
\hline N5: Impulsiveness & 0.36 & ${ }^{* * *}$ & 0.03 & & 0.21 & ${ }^{* *}$ & -0.21 & ${ }^{* *}$ & -0.28 & *** & 0.62 \\
\hline N6: Vulnerability & 0.58 & ${ }^{* * *}$ & -0.23 & ** & -0.20 & ${ }^{*}$ & -0.21 & ${ }^{* *}$ & -0.17 & * & 0.72 \\
\hline \multicolumn{12}{|l|}{ Extraversion } \\
\hline E1: Warmth & -0.22 & $* *$ & 0.52 & ${ }^{* * *}$ & 0.22 & $* *$ & 0.38 & $* * *$ & 0.10 & & 0.73 \\
\hline E2: Gregariousness & -0.14 & & 0.39 & ${ }^{* * *}$ & 0.16 & $*$ & 0.19 & * & 0.12 & & 0.78 \\
\hline E3: Assertiveness & -0.20 & $*$ & 0.59 & ${ }^{* * *}$ & 0.35 & ${ }^{* * *}$ & 0.00 & & 0.24 & ${ }^{* *}$ & 0.63 \\
\hline E4: Activity & 0.00 & & 0.46 & ${ }^{* * *}$ & 0.26 & *** & -0.01 & & 0.26 & ${ }^{* * *}$ & 0.50 \\
\hline E5: Excitement-Seeking & -0.14 & & 0.37 & ${ }^{* * *}$ & 0.31 & ${ }^{* * *}$ & 0.02 & & 0.01 & & 0.48 \\
\hline E6: Positive Emotions & -0.10 & & 0.44 & ${ }^{* * *}$ & 0.42 & ${ }^{* * *}$ & 0.26 & *** & 0.03 & & 0.64 \\
\hline \multicolumn{12}{|l|}{ Openness } \\
\hline O1: Fantasy & 0.12 & & 0.07 & & 0.41 & ${ }^{* * *}$ & 0.04 & & -0.14 & & 0.59 \\
\hline O2: Aesthetics & 0.11 & & 0.03 & & 0.28 & $* * *$ & 0.02 & & 0.09 & & 0.76 \\
\hline O3: Feelings & 0.07 & & 0.22 & $* *$ & 0.32 & ${ }^{* * *}$ & 0.13 & & 0.07 & & 0.55 \\
\hline O4: Actions & -0.24 & $* *$ & 0.26 & ${ }^{* * *}$ & 0.29 & *** & -0.02 & & 0.16 & * & 0.42 \\
\hline O5: Ideas & -0.15 & ${ }^{*}$ & 0.07 & & 0.30 & $* * *$ & -0.15 & & 0.18 & * & 0.73 \\
\hline O6: Values & -0.26 & ${ }^{* * *}$ & -0.02 & & -0.03 & & -0.07 & & 0.04 & & 0.14 \\
\hline \multicolumn{12}{|l|}{ Agreeableness } \\
\hline A1: Trust & -0.18 & ${ }^{*}$ & 0.25 & ** & 0.17 & ${ }^{*}$ & 0.36 & $* * *$ & 0.14 & & 0.78 \\
\hline A2: Straightforwardness & -0.03 & & -0.01 & & -0.05 & & 0.32 & $* * *$ & 0.15 & & 0.75 \\
\hline A3: Altruism & -0.23 & $* *$ & 0.16 & * & 0.08 & & 0.58 & $* * *$ & 0.17 & * & 0.70 \\
\hline A4: Compliance & -0.14 & & -0.08 & & -0.19 & * & 0.41 & $* * *$ & 0.00 & & 0.54 \\
\hline A5: Modesty & 0.00 & & -0.22 & ** & -0.30 & *** & -0.07 & & -0.09 & & 0.61 \\
\hline A6: Tender-Mindedness & 0.07 & & 0.06 & & 0.08 & & 0.33 & $* * *$ & 0.02 & & 0.48 \\
\hline \multicolumn{12}{|l|}{ Conscientiousness } \\
\hline C1: Competent & -0.37 & ${ }^{* * *}$ & 0.19 & * & 0.21 & ${ }^{* *}$ & 0.16 & * & 0.51 & *** & 0.61 \\
\hline C2: Order & -0.10 & & -0.14 & & -0.15 & & 0.05 & & 0.41 & $* * *$ & 0.77 \\
\hline C3: Dutifulness & -0.22 & ${ }^{* *}$ & 0.05 & & -0.12 & & 0.17 & ${ }^{*}$ & 0.43 & ${ }^{* * *}$ & 0.55 \\
\hline C4: Achievement-Striving & -0.26 & ${ }^{* * *}$ & 0.27 & ${ }^{* * *}$ & 0.35 & *** & 0.24 & ${ }^{* *}$ & 0.46 & *** & 0.77 \\
\hline C5: Self-Discipline & -0.34 & ${ }^{* * *}$ & 0.18 & $*$ & 0.11 & & 0.22 & ${ }^{* *}$ & 0.55 & ${ }^{* * *}$ & 0.76 \\
\hline C6: Deliberation & -0.20 & $*$ & -0.12 & & -0.18 & * & 0.07 & & 0.44 & $* * *$ & 0.64 \\
\hline
\end{tabular}

Note: ${ }^{*} p<0.05,{ }^{* *} p<0.01,{ }^{* * *} p<0.001$. 
significant positive correlations were observed between the openness dimension of the TIPI-J and the six openness facets of the NEO-PI-R-J, with a mean of 0.26 . Five out of six agreeableness facets of the NEO-PI-R-J showed significant positive correlations with the agreeableness scale of the TIPI-J, with a mean of 0.32 . All correspondent correlations between the conscientiousness scale of the TIPI-J and the six conscientiousness facets of the NEO-PI-R-J were significantly positive, with a mean of 0.47 .

\section{Joint Factor Analysis}

To examine the Five-Factor structure of the TIPI-J corresponding to the NEO-PI-R-J, five scales of the TIPI-J and the 30 facet scales of the NEO-PI-R-J were used for a factor analysis with maximum likelihood estimation. The eigenvalues of the first eight components were as follows: 7.28, 4.39, 3.60, $2.91,1.88,1.54,1.04$, and .97 . The first five factors accounted for $57.33 \%$ of the variance and the Promax rotated factor pattern is shown in Table 3. The five factors represent Agreeableness, Neuroticism, Conscientiousness, Extraversion, and Openness, respectively. The five scales of the TIPI-J loaded strongly on each corresponding factor.

\section{Discussion}

The results of the present study showed that the correlation coefficients between the five corresponding factors of the TIPI-J and the NEO-PI-R-J ranged from $r=0.46$ to 0.70 . In a previous study, Gosling et al. (2003) reported correlation coefficients ranging from 0.56 to 0.68 between the correspondent subscales of TIPI and the NEO-PI-R in the English version. Muck, Hell, and Gosling (2007) showed that the range of the correlation coefficients was from 0.41 to 0.76 in Germany. The results show that the subscales of the TIPI-J are equivalent to the Big Five personality domains described in other language versions.

With only two items per dimension, there is a concern that the TIPI-J scales might not assess the full breadth of the Big Five dimensions. However, results in this study show substantial correlations between the five scales of the TIPI-J and the corresponding facet scales of the NEO-PI-R-J, supporting the content validity of the TIPI-J. In addition, this study also provides support for the construct validity of the TIPI-J, because content validation provides evidence for an instrument's construct validity (Anastasi, 1988).

Generally, the correlations between the TIPI-J and the facet scores of the NEO-PI-R-J demonstrate that the TIPI-J covers the broad content domain of the Big Five personality dimensions. Gosling et al. (2003) reported that the range of correlation coefficients between the five subscales of TIPI and the corresponding facet factors of the NEO-PI-R are as follows: 0.35 to 0.66 (Neuroticism, absolute value for Emotional Stability values of -0.66 to -0.35 instead of Neuroticism), 0.26 to 0.66 (Extraversion), 0.28 to 0.51 (Openness), 0.20 to 0.59 (Agreeableness), and 0.40 to 65 (Conscientiousness). Muck et al. (2007) reported only 18 significant convergent correlations between the German version of the TIPI and the facet factors of the NEO-PI-R. Although one reason of the insufficiency of the convergent correlations may be smaller sample size $(n=88$; Muck et al., 2007), the TIPI-J seems to assess a broader content of the Big Five
Table 3.

Joint factor analysis of the TIPI-J and facet scores of the Japanese version of the NEO-PI-R-J.

\begin{tabular}{|c|c|c|c|c|c|}
\hline & I & II & III & IV & $\mathrm{V}$ \\
\hline \multicolumn{6}{|l|}{ Agreeableness } \\
\hline A3: Altruism & 0.78 & -0.03 & 0.11 & 0.05 & -0.02 \\
\hline A4: Compliance & 0.69 & -0.06 & -0.06 & -0.34 & -0.05 \\
\hline A1: Trust & 0.66 & -0.08 & 0.02 & 0.14 & 0.00 \\
\hline A2: Straightforwardness & 0.63 & 0.19 & 0.24 & -0.13 & -0.09 \\
\hline Agreeableness(TIPI-J) & 0.63 & -0.17 & 0.00 & -0.15 & 0.05 \\
\hline A6: Tender-Mindedness & 0.62 & 0.33 & -0.04 & 0.04 & 0.12 \\
\hline A5: Modesty & 0.17 & 0.08 & 0.00 & -0.40 & -0.09 \\
\hline \multicolumn{6}{|l|}{ Neuroticism } \\
\hline N1: Anxiety & 0.13 & 0.83 & 0.18 & -0.16 & 0.15 \\
\hline N6: Vulnerability & 0.03 & 0.80 & -0.08 & 0.01 & -0.02 \\
\hline N3: Depression & -0.06 & 0.74 & -0.04 & -0.05 & -0.06 \\
\hline Neroticism(TIPI-J) & -0.07 & 0.70 & -0.05 & 0.01 & 0.05 \\
\hline N4: Self-Consciousness & 0.04 & 0.70 & 0.03 & -0.20 & 0.10 \\
\hline N2: Angry Hostility & -0.55 & 0.62 & 0.10 & 0.24 & -0.04 \\
\hline N5: Impulsiveness & -0.23 & 0.28 & -0.42 & 0.28 & 0.15 \\
\hline \multicolumn{6}{|l|}{ Conscientiousness } \\
\hline C5: Self-Discipline & 0.09 & -0.18 & 0.73 & 0.12 & -0.01 \\
\hline C3: Dutifulness & 0.09 & 0.08 & 0.72 & 0.03 & -0.14 \\
\hline C6: Deliberation & 0.02 & 0.04 & 0.72 & -0.18 & 0.00 \\
\hline Conscientiousness(TIPI-J) & -0.04 & 0.09 & 0.68 & 0.15 & 0.04 \\
\hline C2: Order & 0.00 & 0.18 & 0.68 & -0.11 & -0.03 \\
\hline $\mathrm{C} 1$ : Competent & -0.13 & -0.20 & 0.64 & 0.20 & 0.17 \\
\hline C4: Achievement-Striving & 0.20 & -0.07 & 0.52 & 0.20 & 0.25 \\
\hline \multicolumn{6}{|l|}{ Extraversion } \\
\hline Extraversion(TIPI-J) & 0.01 & -0.12 & -0.08 & 0.81 & -0.21 \\
\hline E3: Assertiveness & -0.17 & -0.05 & 0.11 & 0.78 & -0.04 \\
\hline E4: Activity & -0.20 & 0.09 & 0.18 & 0.72 & -0.07 \\
\hline E2: Gregariousness & 0.41 & 0.16 & 0.04 & 0.53 & -0.09 \\
\hline E1: Warmth & 0.54 & -0.03 & -0.10 & 0.52 & -0.08 \\
\hline E6: Positive Emotions & 0.38 & 0.04 & -0.17 & 0.48 & 0.27 \\
\hline E5: Excitement-Seeking & 0.07 & 0.01 & -0.14 & 0.40 & 0.11 \\
\hline \multicolumn{6}{|l|}{ Openness } \\
\hline O2: Aesthetics & 0.06 & 0.19 & 0.09 & -0.15 & 0.71 \\
\hline O1: Fantasy & -0.01 & -0.06 & -0.30 & -0.08 & 0.65 \\
\hline O5: Ideas & -0.22 & -0.11 & 0.28 & -0.10 & 0.54 \\
\hline Openness(TIPI-J) & -0.08 & -0.21 & -0.10 & 0.23 & 0.51 \\
\hline O3: Feelings & 0.16 & 0.15 & 0.00 & 0.18 & 0.51 \\
\hline O6: Values & -0.05 & -0.33 & -0.06 & -0.20 & 0.13 \\
\hline O4: Actions & -0.02 & -0.25 & -0.01 & 0.19 & 0.19 \\
\hline Inter-factor correlation & I & II & III & IV & $\mathrm{V}$ \\
\hline I & - & -0.20 & 0.22 & 0.25 & 0.13 \\
\hline II & & - & -0.33 & -0.36 & -0.03 \\
\hline III & & & - & 0.10 & -0.02 \\
\hline IV & & & & - & 0.48 \\
\hline $\mathrm{V}$ & & & & & - \\
\hline
\end{tabular}

Note: I. Agreeableness; II. Neuroticism; III. Conscientiousness; IV. Extraversion; V. Openness. 
personality dimensions than the German version, and was equivalent to the original English version. However, nonsignificant correlations between the TIPI-J scales and the facet scores of the NEO-PI-R-J were found for the Values and Modesty facets, suggesting that these facets may not be adequately covered by the TIPI-J. However, the problem may not lie with the content validity of the TIPI-J because the Value facet had particularly low reliabilities in this study. Additionally, a previous study in Japan (Shimonaka, Nakazato, Gondo, \& Takayama, 1998) reported that the Modesty facet was not successfully comprised in the Agreeableness factor, and it yielded high negative factor loading on the Extraversion and Openness factors. The correlation analyses in this study show that the Modesty facet correlated negatively with both the Extraversion and Openness factors of the TIPI-J, whereas the joint factor analysis indicated that it is comprised in Extraversion rather than in Agreeableness. Another reason for the lack of correlation between the Modesty facet and Agreeableness of the TIPI-J involves the characteristics of the TIPI itself. The correlation coefficient between these scores was reported to be 0.23 for the English version (Gosling et al., 2003) and non-significant for the German version (Muck et al., 2007). Gosling et al. (2003) also reported that the correlation coefficient between the Modesty facet and Agreeableness of the BFI (John \& Srivastava, 1999) was 0.23 . This pattern suggests that the weak correlation between the scores may reflect something about the Modesty facet of the NEO-PI-R itself, rather than an inadequacy of the very brief measures of agreeableness.

This study also shows that the correlations between the TIPI-J and the facet scores of the NEO-PI-R-J are not in complete agreement with the predicted relations. For example, the Angry Hostility facet had higher correlation with the Agreeableness scale than with the Neuroticism scale, with which it is theoretically more strongly related. However, as before, it is not clear whether the failure of all scales to converge as predicted can be attributed entirely to problems with the TIPI-J.

The joint factor analysis in this study showed that the five subscales of the TIPI-J have a Big Five personality structure that corresponds to the NEO-PI-R-J. The results indicate that the five subscales of the TIPI-J seem to be good indicator of the Big Five personality dimensions.

\section{Conclusion}

Theoretically, the TIPI-J, being a very brief measure, might be expected to correlate less strongly with scores of other scales than longer measures because of the increased measurement error associated with brief scales. However, as always, there are trade-offs between ease-of-use and validity to consider in choosing the most suitable measure. Where only short measures are needed, the TIPI-J is clearly beneficial in economizing time and space. The TIPI-J is currently the only brief measure of the Big Five dimensions available in Japan. Furthermore, it facilitates comparisons across cultures because the TIPI is used in many studies all around the world. As a result, the TIPI-J is expected to be used in a wide variety of research settings in Japan.

\section{REFERENCES}

Anastasi, A. (1988). Psychological testing (6th ed.). New York: Mac- millan.

Aoki, T. (1971). A psycho-lexical study of personality trait words: Selection, classification and desirability ratings of 455 words. The Japanese Journal of Psychology, 42, 1-13. http://dx.doi.org/10.4992/jjpsy.42.1

Aoki, T. (1976). Personality structures constructed from a questionnaire containing many personality spheres. The Japanese Journal of Personality, 47, 239-249. http://dx.doi.org/10.4992/jipsy.47.239

Aronson, Z. H., Reilly, R. R., \& Lynn, G. S. (2006). The impact of leader personality on new product development teamwork and performance: The moderating role of uncertainty. Journal of Engineering and Technology Management, 23, 221-247.

http://dx.doi.org/10.1016/j.jengtecman.2006.06.003

Bernard, L. C., Walsh, R. P., \& Mills, M. (2005). Ask once, may tell: Comparative validity of single and multiple item measurement of the Big-Five personality factors. Counseling and Clinical Psychology Journal, 2, 40-57.

Bruce, V., Young, A., Allport, G. W., \& Odbert, H. S. (1936). Traitnames: A psycho-lexical study. Psychological Monographs, 47, i171. http://dx.doi.org/10.1037/h0093360

Costa, P. T., Jr., \& McCrae, R. R. (1992). Revised NEO Personality Inventory (NEO-PI-R) and NEO Five-Factor Inventory (NEO-FFI) professional manual. Odessa, FL: Psychological Assessment Resources.

Credé, M., Harms, P., Niehorster, S., \& Gaye-Valentine, A. (2012). An evaluation of the consequences of using short measures of the Big Five personality traits. Journal of Personality and Social Psychology, 102, 874-888. http://dx.doi.org/10.1037/a0027403

Fujishima, Y., Yamada, N., \& Tsuji, H. (2005). Construction of short form of Five Factor Personality Questionnaire. The Japanese Journal of Personality, 13, 231-241.

http://dx.doi.org/10.2132/personality.13.231

Gosling, S. D., Rentfrow, P. J., \& Swann, W. B., Jr. (2003). A very brief measure of the Big-Five personality domains. Journal of Research in Personality, 37, 504-528.

http://dx.doi.org/10.1016/S0092-6566(03)00046-1

Haynes, S. N., Richard, D. C. S., \& Kubany, E. S. (1995). Content validity in psychological assessment: A functional approach to concepts and methods. Psychological Assessment, 7, 238-247. http://dx.doi.org/10.1037/1040-3590.7.3.238

Jonason, P. K., \& Webster, G. D. (2010). The Dirty Dozen: A concise measure of the Dark Triad. Psychological Assessment, 22, 420-432. http://dx.doi.org/10.1037/a0019265

Kashiwagi, S., Wada, S., \& Aoki, T. (1993). The BIG FIVE and the oblique primary pattern for the items of the ACL, Japanese version. The Japanese Journal of Psychology, 64, 153-159.

http://dx.doi.org/10.4992/jipsy.64.153

Kashiwagi, S., Tsuji, H., Fujishima, Y., \& Yamada, N. (2005). Reevaluation of Tsuji's psycholexical study in terms of the Big Five personality factors. The Japanese Journal of Psychology, 76, 368374. http://dx.doi.org/10.4992/jjpsy.76.368

Muck, P. M., Hell, B., \& Gosling, S. D. (2007). Construct validation of a short five-factor model instrument: A self-peer study on the German adaptation of the Ten-Item Personality Inventory (TIPI-G). European Journal of Psychological Assessment, 23, 166-175. http://dx.doi.org/10.1027/1015-5759.23.3.166

Murakami, Y., \& Murakami, T. (1999). Manual of big five. Tokyo: Gakugeitosho.

Murakami, Y. (2003). Big five and psychometric conditions for their extraction in Japanese. The Japanese Journal of Personality, 11, $70-85$.

Namikawa, T., Tani, I., Wakita, T., Kumagai, R., Nakane, A., \& Noguchi, H. (2012). Development of a short form of the Japanese BigFive Scale, and a test of its reliability and validity. The Japanese Journal of Psychology, 83, 91-99. http://dx.doi.org/10.4992/jipsy.83.91

Oshio, A., Abe, S., \& Cutrone, P. (2012). Development, reliability, and validity of the Japanese version of Ten Item Personality Inventory (TIPI-J). The Japanese Journal of Personality, 21, 40-52. http://dx.doi.org/10.2132/personality.21.40 
Rammstedt, B., \& John, O. P. (2007). Measuring personality in one minute or less: A 10-item short version of the Big Five Inventory in English and German. Journal of Research in Personality, 41, 203212. http://dx.doi.org/10.1016/j.jrp.2006.02.001

Robins, R. W., Hendin, H. M., \& Trzesniewski, K. H. (2001). Measuring global self-esteem: Construct validation of a single-item measure and the Rosenberg Self-Esteem Scale. Personality and Social Psychology Bulletin, 27, 151-161.

http://dx.doi.org/10.1177/0146167201272002

Shimonaka, Y., Nakazato, K., Gondo, Y., \& Takayama, M. (1998). Construction and factorial validity of the Japanese NEO-PI-R. The Japanese Journal of Personality, 6, 138-147.

Shimonaka, Y., Nakazato, K., Gondo, Y., \& Takayama, M. (1999). Revised NEO-Personality Inventory (NEO-PI-R) and NEO FiveFactor Inventory (NEO-FFI) manual for the Japanese version. Tokyo: Tokyo Shinri.

Thalmeyer, A. G., Saucier, G., \& Eigenhuis, A. (2011). Comparative validity of brief to medium-length Big Five and Big Six personality questionnaires. Psychological Assessment, 23, 995-1009. http://dx.doi.org/10.1037/a0024165

Uchida, T. (2002). Effects of the speech rate on speakers' personality-trait impressions. The Japanese Journal of Psychology, 73, 131139. http://dx.doi.org/10.4992/jjpsy.73.131

Wada, S. (1996). Construction of the Big Five Scales of personality trait terms and concurrent validity with NPI. The Japanese Journal of Psychology, 67, 61-67.

http://dx.doi.org/10.4992/jipsy.67.61

Woods, S. A., \& Hampson, S. E. (2005). Measuring the Big Five with single items using a bipolar response scale. European Journal of Personality, 19, 373-390. http://dx.doi.org/10.1002/per.542

Yamagata, S., Suzuki, A., Ando, J., Ono, Y., Kijima, N., Yoshimura, K., \& Jang, K. L. (2006). Is the genetic structure of human personality universal? A cross-cultural twin study from North America, Europe, and Asia. Journal of Personality and Social Psychology, 90, 987-998. http://dx.doi.org/10.1037/0022-3514.90.6.987 